\title{
Los nuevos caminos de la Traducción
}

\section{The New Paths of Translation}

\section{PREFACIO}

\author{
José M. BUSTOS GISBERT y Jesús TORRES DEL REY \\ Universidad de Salamanca \\ jbustos@usal.es / jtorres@usal.es
}

En el presente momento histórico, en el que se debate el fin del trabajo tal y como lo conocemos (Rifkin 2010), cuando se vaticina la inevitable transformación o desaparición de innumerables profesiones bajo la presión de la globalización y de revoluciones tecnológicas como la que propone la inteligencia artificial, los estudios de Traducción e Interpretación se encuentran en una tesitura crucial, tanto en la recepción de las consecuencias como en las formas de percepción y de distribución de dichos cambios. Esta posición de encrucijada y, a la vez, de centralidad de la traducción (en lo que sigue, con inclusión de la interpretación y la localización) viene propiciada por la efervescencia de la traducción automática, el reconocimiento del habla, los diferentes modos de recreación y reproducción audiovisual y multimedia, y la necesidad de acceso instantáneo y aparentemente universal a la información, la cultura y el ocio; pero, a la vez, por las profundas asimetrías, incomprensiones y grietas de la globalización, y la creciente imposición de la productividad como fin absoluto, mientras parece fragmentarse, democratizarse o relativizarse el concepto de calidad también en nuestro ámbito (Koby et al. 2014). 
Para afrontar estos profundos cambios, no cabe sino reafirmar la importancia de la traducción como práctica productiva lingüístico-cultural de interacción persona-ordenador (O'Brien 2012), dotada de una orientación fundamentalmente profesional; pero, a la vez, como un proceso íntimamente humano de análisis, negociación y realización de la diversidad y la multitud de voces y coordenadas personales, sociales y culturales: esto es, la traducción como garante de la sostenibilidad cultural. En cierto modo, las soluciones de y para la traducción pueden reflejar las que ya avanzaba Rifkin (2010) y que consisten en promover la transformación social y el renacimiento del espíritu humano. En gran medida, esto no supone sino aprender a reconocer el carácter ubicuo, ineludible, catártico y revelador de la traducción; y, en este sentido también, aprender a traducirnos, los unos a los otros y a nuestro entorno, de manera más eficiente, diversa, colaborativa y con apoyo tecnológico, pero siempre comprendiendo sus consecuencias como una responsabilidad última del ser humano.

Situados como estamos en pleno torbellino de digitalidad y globalidad traducidas y traductoras, hemos querido seleccionar aquí una serie de artículos que nos permitan poner a prueba la solidez de los sustratos de la disciplina y la profesión de la traducción (el lenguaje, la terminología, la deontología y el estatus profesional, la enseñanza de la traducción y los soportes, herramientas y procesos de la actividad), sometiéndolos para ello al examen de algunos de los fenómenos más pujantes y en vías de evolución de nuestro ámbito: la posedición de traducción automática, la localización, la interpretación, la evaluación de la calidad, la explotación de corpus digitales, o los productos y procesos audiovisuales.

Así, en este número de la revista CLINA, comenzamos abordando el soporte audiovisual. M. ${ }^{a}$ Carmen Gómez Pérez se pregunta cuál es el tratamiento de la polifonía multilingüe en el doblaje cinematográfico en distintas culturas, y si influyen más las intenciones creativas del autor o la percepción o posición de poder de la lengua extranjera, alemana en este caso, en este proceso de traducción subordinada.

Katrin Pieper sitúa los focos sobre los procesos de censura de la sexualidad en películas extranjeras llevada a cabo por la dictadura del Estado Novo portugués (19331974). Mediante el ejemplo de una película alemana (Helga, de 1967) que, excepcionalmente, fue aprobada (con cortes) para su proyección, se reconstruye el posible proceso de creación de subtítulos para el análisis preliminar de la censura, y se debate cómo los traductores lograron encauzar el discurso de la película dentro de los parámetros ideológicos del régimen.

Elena Palacio Alonso inaugura, a continuación, un bloque de artículos centrado en las aulas, en este caso de interpretación. La autora reflexiona sobre la interiorización de aspectos deontológicos relativos a la profesión de intérprete por parte de los estudiantes de grado, y aborda la necesidad de trasladar el problema más allá de la figura del cliente para situar la sociedad como principal beneficiario en la era de la globalidad en permanente traducción. 
La competencia intercultural es, en relación con la autocomprensión del futuro traductor, una de las dimensiones más importantes que el estudiante debe adquirir desde el comienzo de los estudios. Precisamente, Laura González Fernández propone en su capítulo nuevas perspectivas teóricas y un modelo práctico innovador para el desarrollo del papel de mediador intercultural del traductor, a través de la enseñanza de lenguas en la formación en traducción e interpretación. Para ello, realiza un estudio diacrónico de esta competencia en nuestro ámbito de enseñanza, analiza las prácticas metodológicas más exitosas, y finaliza con un diseño de actividades específicas para este fin, tomando como modelo el par español-inglés.

La enseñanza de lenguas extranjeras en los estudios de Traducción e Interpretación es también el foco principal de atención de la aportación de Irene Doval Reixa. En este caso, se centra en niveles avanzados de la formación, y explora la utilidad de los corpus paralelos como metodología didáctica y, a la vez, herramienta para la obtención de resultados de aplicación directa en el proceso de aprendizaje de lenguas extranjeras y la propia traducción. Tras repasar los procesos de elaboración de corpus, y sus vías de inserción en la enseñanza, el artículo emplea el ejemplo del corpus paralelo bilingüe español/alemán, PaGeS y resalta la capacidad de estos instrumentos de "aprendizaje basado en datos» para fomentar en el estudiantado la competencia de aprender a aprender.

En un siguiente bloque, se tratan aspectos de profunda actualidad profesional. En el primero de ellos, Tabea de Wille y Montserrat Bermúdez-Bausela se atreven a llevar a cabo una investigación empírica en relación con la percepción de calidad a partir de un componente extrínseco como es la mayor o menor experiencia profesional declarada (verazmente o no) por los traductores. El experimento les permite, además, analizar no solo las cualidades que se les suponen a los traductores y localizadores profesionales, sino la mayor o menor capacidad de juicio que tienen los expertos frente a los noveles ante la calidad de una traducción.

A continuación, tres artículos estudian diversas dimensiones de la traducción automática. Coral Diez Carbajo explora las cualidades que deben tener las herramientas de posedición para que no solo cumplan con las funciones esperadas, sino que sean usables. A partir de las opiniones de expertos en características de utilidad para la posedición (antes, durante y después de la misma), y de un análisis de la interacción de las herramientas basado en las conclusiones de estudios genéricos sobre experiencia de usuario, usabilidad e interacción persona-ordenador, la autora realiza una panorámica del presente y el futuro de estas herramientas que se antojan fundamentales para el trabajo del traductor.

Por su lado, Anthony Hartley, Beibei He, Masao Utiyama, Hitoshi Isahara y Eiichiro Sumita presentan un novedoso trabajo surgido a propósito del Mundial de Rugby de 2019, que se celebra en Japón. El proyecto ScrumSourcing, en el que participan, pretende dotar de viabilidad al servicio de traducción automática neuronal creado para

José M. BUSTOS GISBERT y Jesús TORRES DEL REY Los nuevos caminos de la Traducción 
facilitar la interacción entre aficionados de habla japonesa e inglesa. Dicho servicio se encuentra con importantes dificultades debido a la asimetría entre los corpus de ambos idiomas y al propio subdesarrollo terminológico y discursivo de este ámbito de comunicación en japonés. Para paliarlas, un equipo de voluntarios lleva a cabo un proceso de entrenamiento del sistema mediante posedición, tras la adaptación inicial de determinadas características comparativas del lenguaje de los comentarios sobre rugby.

Para terminar con este particular ámbito de actualidad, Astrid Schmidhofer y Natalie Mair dirigen su atención a la formación de traductores en traducción automática, en particular en universidades austriacas. Para ello, llevan a cabo un experimento en una clase de traducción general y otra de traducción especializada, en el que valoran las actitudes y las aptitudes de estudiantes de grado y posgrado frente a textos traducidos automáticamente, tanto en el proceso de posedición como de comparación de resultados de traducción automática con traducción humana. En último término, el objetivo de este tipo de investigación pretende fomentar un uso adecuado de los medios tecnológicos al alcance de los estudiantes, así como promover una conciencia abierta, pero crítica, de los mismos.

El último bloque de este número se centra en uno de los sustratos de mayor relevancia reconocida para la traducción, particularmente en contextos de especialización y de intervención de la tecnología: la terminología. Así, Ismarie Díaz Flores realiza una exploración del entramado cultural e histórico que subyace a las configuraciones terminológicas en el ámbito culinario en Puerto Rico. Para ello, se analizan cinco libros de recetas a la luz del contexto cultural, el dominio, la producción textual y el uso de los términos en el corpus, y se propone, finalmente, una base de datos que considera los aspectos culturalmente marcados de esta terminología. La integración de los citados aspectos de análisis para la representación conceptual del ámbito culinario se realiza en el artículo mediante el ejemplo de la categoría de ingredientes denominada viandas.

En el último capítulo Rossella Michienzi evalúa la heteroglosia de la terminología, extraída a través de un software de concordancias, del Informe de la comisión nacional sobre la desaparición de personas de Argentina (Nunca Más). Mediante un minucioso análisis de la evolución connotativa de los diversos términos del informe en una sociedad marcada por el trauma, y a partir de aquellos estudios de la traducción que se centran en los conceptos de ideología y poder, la autora subraya la necesidad de ir más allá de las representaciones de significado dominantes y estáticas. Así, buscando en los silencios y los ruidos de las palabras, es decir, traduciendo la sociedad y a las personas, se podrá lograr la sostenibilidad intercultural, respetar y dar voz al otro, no resignarse al olvido.

Los editores

José M. Bustos GISBERT y Jesús TORRES DEL REY Los nuevos caminos de la Traducción

\section{CLINA}

vol. 4-2, December 2018, 7-11

eISSN: 2444-1961

Ediciones Universidad de Salamanca - CC BY-NC-ND 


\section{REFERENCIAS}

KoBY, Geoffrey S., Paul FieldS, Daryl R. HAGUe, Arle LOMmel y Alan Melby. 2014. "Defining Translation Quality». Revista Tradumàtica (12). https://doi.org/10.5565/rev/tradumatica.76.

O'BRIEN, Sharon. 2012. «Translation and human-computer interaction». Translation Spaces, 1: 101-122. https://doi.org/10.1075/ts.1.05obr .

RIFKIN, Jeremy. 2010 [1995]. El fin del trabajo. Nuevas tecnologías contra puestos de trabajo: el nacimiento de una nueva era. Trad.: Sánchez Gallego, Guillermo. Barcelona: Paidós. 
